\title{
Potentially modifiable predictors of adverse neonatal and maternal outcomes in pregnancies with gestational diabetes mellitus: can they help for future risk stratification and risk-adapted patient care?
}

Maria-Christina Antoniou ${ }^{1 *}$, Leah Gilbert ${ }^{2}$, Justine Gross²,3, Jean-Benoît Rossel², Céline J. Fischer Fumeaux, Yvan Vial ${ }^{2}$ and Jardena J. Puder ${ }^{2}$

\begin{abstract}
Background: Gestational diabetes mellitus (GDM) exposes mothers and their offspring to short and long-term complications. The objective of this study was to identify the importance of potentially modifiable predictors of adverse outcomes in pregnancies with GDM. We also aimed to assess the relationship between maternal predictors and pregnancy outcomes depending on $\mathrm{HbA1c}$ values and to provide a risk stratification for adverse pregnancy outcomes according to the prepregnancy BMI (Body mass index) and HbA1C at the 1st booking.

Methods: This prospective study included 576 patients with GDM. Predictors were prepregnancy BMI, gestational weight gain (GWG), excessive weight gain, fasting, 1 and 2 -h glucose values after the $75 \mathrm{~g}$ oral glucose challenge test (oGTT), HbA1c at the 1st GDM booking and at the end of pregnancy and maternal treatment requirement. Maternal and neonatal outcomes such as cesarean section, macrosomia, large and small for gestational age (LGA, SGA), neonatal hypoglycemia, prematurity, hospitalization in the neonatal unit and Apgar score at 5 min $<7$ were evaluated. Univariate and multivariate regression analyses and probability analyses were performed.
\end{abstract}

Results: One-hour glucose after OGTT and prepregnancy BMI were correlated with cesarean section. GWG and $\mathrm{HbA1c}$ at the end pregnancy were associated with macrosomia and LGA, while prepregnancy BMI was inversely associated with SGA. The requirement for maternal treatment was correlated with neonatal hypoglycemia, and $\mathrm{HbA} 1 \mathrm{c}$ at the end of pregnancy with prematurity (all $p<0.05$ ). The correlations between predictors and pregnancy complications were exclusively observed when $\mathrm{HbA} 1 \mathrm{c}$ was $\geq 5.5 \%$ (37 mmol/mol). In women with prepregnancy $\mathrm{BMI} \geq 25 \mathrm{~kg} / \mathrm{m}^{2}$ and $\mathrm{HbA1c} \geq 5.5 \%(37 \mathrm{mmol} / \mathrm{mol})$ at the $1 \mathrm{st}$ booking, the risk for cesarean section and LGA was nearly doubled compared to women with BMl with $<25 \mathrm{~kg} / \mathrm{m}^{2}$ and $\mathrm{HbA} 1 \mathrm{c}<5.5 \%(37 \mathrm{mmol} / \mathrm{mol})$.

Conclusions: Prepregnancy BMI, GWG, maternal treatment requirement and HbA1c at the end of pregnancy can predict adverse pregnancy outcomes in women with GDM, particularly when $\mathrm{HbA} 1 \mathrm{c}$ is $\geq 5.5 \%(37 \mathrm{mmol} / \mathrm{mol})$. Stratification based on prepregnancy BMI and $\mathrm{HbA1c}$ at the 1st booking may allow for future risk-adapted care in these patients.

Keywords: Gestational diabetes, HbA1c, Pregnancy outcomes, Risk stratification

\footnotetext{
* Correspondence: maria-christina.antoniou@chuv.ch

${ }^{1}$ Pediatric Service, Department Woman-Mother-Child, Lausanne University

Hospital, Lausanne, Switzerland

Full list of author information is available at the end of the article
}

(c) The Author(s). 2019 Open Access This article is distributed under the terms of the Creative Commons Attribution 4.0 International License (http://creativecommons.org/licenses/by/4.0/), which permits unrestricted use, distribution, and reproduction in any medium, provided you give appropriate credit to the original author(s) and the source, provide a link to the Creative Commons license, and indicate if changes were made. The Creative Commons Public Domain Dedication waiver (http://creativecommons.org/publicdomain/zero/1.0/) applies to the data made available in this article, unless otherwise stated. 


\section{Background}

Gestational Diabetes Mellitus (GDM) is defined as diabetes first diagnosed in the second or third trimester of pregnancy that is not preexisting, type 1 or type 2 diabetes [1]. The incidence of GDM has dramatically increased during the past decades reflecting the ongoing epidemic in obesity and type 2 diabetes [2, 3]. In Switzerland, using the International Association of Diabetes and Pregnancy Study Group (IADPSG) Criteria, GDM is diagnosed in $10.9 \%$ of pregnancies [4]. GDM exposes the mothers and their offspring to short and long-term complications [4-7]. Previous studies have shown the beneficial effect of GDM treatment on neonatal outcomes such as birth weight and fat, large for gestational age (LGA) and shoulder dystocia, as well as maternal outcomes, including cesarean section and preeclampsia $[8,9]$.

Several potentially modifiable predictors regarding adverse outcomes have been studied. Maternal overweight and obesity increase the risk for neonatal complications $[10,11]$. In pregnancies with GDM, gestational weight gain (GWG) is associated with cesarean section and LGA [12]. The implementation of the Institute of Medicine guidelines of BMI-based weight gain [13] has also increased knowledge about the deleterious effect of excess gestational weight gain (EWG) on neonatal outcomes [14-16] . Nevertheless, as far as we know, there is no study evaluating whether GWG or EGW is a more potent predictor of adverse neonatal outcomes.

Maternal metabolic control affects neonatal birth outcomes. The correlation between glycated hemoglobin (HbA1c) at GDM diagnosis and neonatal complications remains controversial [17-20]. Recent studies have demonstrated the association between third trimester $\mathrm{HbAlc}$ and adverse neonatal outcomes in offspring of treated women [21, 22]. Few studies have aimed to identify third trimester HbA1c cutoffs above which neonatal complications are increased; nevertheless, specific HbA1c cutoffs are still lacking [22-24]. Maternal glucose values during the oral glucose tolerance test (oGTT) at 24-28 weeks of gestational age have been linked to adverse neonatal outcomes in previous studies $[25,26]$, although their value is different in the context of a treated GDM population.

Finally, a recent study in a population with GDM, demonstrated that there is an association between the need for medical glucose-lowering treatment and adverse pregnancy outcomes including cesarean section, LGA, SGA, and prematurity [27]. On the other side, a recent Atlantic DIP study did not find any difference in neonatal hypoglycemia rates in women with GDM treated with insulin vs nutritional care [28]. Further studies are needed to evaluate whether the risk of neonatal hypoglycemia is higher if a maternal medical treatment is required in order to create evidence-based guidelines for neonatal glucose monitoring or other adverse outcomes.

The objective of this study was: 1) to identify the respective importance of potentially modifiable predictors of adverse neonatal and maternal outcomes in the context of a treated population of women with GDM. 2) to assess the relationship between these predictors and outcomes depending on HbA1c values. 3) to evaluate the impact of absolute GWG versus of EGW on these outcomes. 4) to provide a risk stratification for adverse pregnancy outcomes depending on prepregnancy Body Mass Index (BMI) and HbA1c at the 1st booking at the GDM clinic.

\section{Methods}

\section{Study design and patient population}

This is a prospective observational study, which included pregnant women with GDM followed in the Diabetes and Pregnancy Unit in the Centre Hospitalier Universitaire Vaudois (CHUV), Lausanne, Switzerland, between April 2012 and October 2017.

\section{GDM diagnosis, treatment and follow-up}

GDM was diagnosed according to the IADPSG Criteria [29]. Thus, the diagnosis of GDM was confirmed if fasting blood glucose (FBG) was $\geq 5.1 \mathrm{mmol} / \mathrm{l}$ and/or $1 \mathrm{~h}$ blood glucose was $\geq 10.0 \mathrm{mmol} / \mathrm{l}$ and/or $2 \mathrm{~h}$ blood glucose was $\geq 8.5 \mathrm{mmol} / \mathrm{l}$, following a $75 \mathrm{~g}$ oGTT. The treatment was based on the current guidelines of the American Diabetes Association [30] and of the Endocrine Society [31]. At their first clinical appointment, patients were seen by a nurse specialized in GDM or a medical doctor, received information on GDM and were taught how to perform the capillary blood glucose test. A dietician saw women 1 week later and provided them with recommendations regarding their GDM, lifestyle management and weight gain during pregnancy. Women were encouraged to increase physical activity and had the possibility to receive physical activity counseling by a physiotherapist, as well as to participate in GDM physical activity groups. According to international and local guidelines (Vaud Cantonal Diabetes Program [32, 33]), women were asked to control their capillary glucose values 4 times per day (fasting blood glucose (FBG) in the morning and 2-h (or 1-h) postprandial blood glucose after each meal). Additional glucose controls were recommended on an individual basis, if needed. If despite lifestyle changes, glucose values remained above targets two or more times during a 1 to 2-week period (FBG > $5.3 \mathrm{mmol} / \mathrm{l}, 1$-h postprandial glucose $>8 \mathrm{mmol} / \mathrm{l}$ and 2-h postprandial glucose $>7 \mathrm{mmol} / \mathrm{l}$ ), metformin or insulin treatment was introduced, depending on glucose values (i.e. insulin in case of relatively high values), patient characteristics (i.e BMI) and patient preference. Short 
acting insulin analogues were introduced and adapted to achieve 1 - $\mathrm{h}$ postprandial glucose $\leq 8 \mathrm{mmol} / \mathrm{l}$ or 2 -h postprandial glucose $\leq 7 \mathrm{mmol} / \mathrm{l}$, and long acting insulin analogues to achieve FBG $\leq 5.3 \mathrm{mmol} / \mathrm{l}$.

\section{Maternal and neonatal anthropometric and metabolic parameters}

Prepregnancy Body Mass index (BMI) was calculated based on self-reported pre-pregnancy weight or retrieved from medical charts and measured height on the first visit at the GDM clinic, using the formula weight $(\mathrm{kg}) /$ $[\text { height }(\mathrm{m})]^{2}$. First booking BMI was calculated based on the measured weight and height on the first visit at the GDM clinic. Gestational weight gain was determined as the difference between the last weight measured before delivery and pre-pregnancy weight. Excessive gestational weight gain (EGW) was defined as gestational weight gain exceeding the thresholds established by the Institute of Medicine (IOM) Guidelines 2009 for the respective maternal pre-pregnancy BMI category [13]. HbA1c levels were measured both on the 1st booking at the GDM clinic and at the end of pregnancy (last visit before delivery). HbA1c at the end of pregnancy was only performed after March 2015. Hba1c was measured using a chemical photometric method (conjugation with boronate; Afinion ${ }^{\circ}$ ). The Afinion ${ }^{\circ}$ analyzer has shown to have similar accuracy and precision compared to the highperformance liquid chromatography (HPLC), which is IFCC (International Federation of Clinical Chemistry and Laboratory Medicine) standardized and DCCT (Diabetes Control and Complications Trial) aligned [34]. The maternal treatment was documented and classified in 2 categories (no treatment, treatment with metformin and/or insulin). Maternal ethnicity was also recorded and classified in Low (Europe, North America) and High Risk (Asia, Central and South America, Africa, Oceania) ethnic groups [30]. Cesarean section was the only maternal complication assessed by this study; the decision for cesarean section indication was taken by the mother's obstetrician.

Neonatal growth parameters such as weight (g) and length $(\mathrm{cm})$, and head circumference were documented at birth as an absolute value; percentiles and z-scores for each of the above mentioned parameters were calculated using the Intergrowth 21st newborn size application tool [35]. Large-for-gestational-age was defined as newborn weight $>90$ th percentile for sex and gestational age. Small-for-gestational-age birth weight was defined as newborn weight $<10$ th percentile for sex and gestational age. Macrosomia was defined as birth weight $\geq 4000 \mathrm{~g}$. Prematurity was defined as gestational age $<37$ weeks. Gestational age was calculated according to the date of the last menstruations, or as assessed by the fetal ultrasound in the cases where gestational age was corrected during the early in-utero ultrasound evaluation. According to the center protocol, all GDM neonates received feeding in the first $2 \mathrm{~h}$ of life and were fed every $2-3 \mathrm{~h}$ during the first $48 \mathrm{~h}$ in order to prevent neonatal hypoglycemia. Systemic blood glucose monitoring was conducted according [36] in all newborns the frequency of the controls (minimum 3) depending on whether the mother was treated or not with insulin during her pregnancy (minimum 8 controls, during $48 \mathrm{~h}$ in case of maternal treatment). Neonatal glycemia was also measured if symptoms suggested hypoglycemia. Hypoglycemia was defined as capillary or venous glucose value $\leq 2.5 \mathrm{mmol} / \mathrm{l}$. The blood glucose value (capillary or venous) was also verified in the CHUV central laboratory if capillary glycemia measured by the glucometer was $\leq 2.5 \mathrm{mmol} / \mathrm{l}$. Neonates were hospitalized for intravenous glucose infusion when they presented a symptomatic hypoglycemia, or a glycemia $\leq 2.0 \mathrm{mmol} / \mathrm{L}$, or more than one hypoglycemia $\leq 2.5 \mathrm{mmol} / \mathrm{L}$ despite administration of additional milk.

Other assessed neonatal complications were stillbirth or death, Apgar score at $5 \mathrm{~min}<7$, jaundice requiring phototherapy and hospitalization in the neonatal unit.

Neonatal data were obtained from the center patient electronic medical chart for all newborns born in the CHUV. In the cases where delivery took place in another hospital or clinic, anthropometric parameters at birth were provided, if possible, by the mother during her 6-8 weeks post partum visit at the Diabetes and Pregnancy Unit.

\section{Ethics}

Signed informed consent to use maternal and infant data was obtained from all participating women. Participation in the study did not interfere with the typical care that patients receive during pregnancy and after childbirth. The study was conducted in accordance with the guidelines of the declaration of Helsinki, and good clinical practice. The Human Research Ethics Committee of the Canton de Vaud approved the study protocol (326/15).

\section{Predictors and outcomes}

The predictors in our study included the following potentially modifiable maternal anthropometric and metabolic parameters: prepregnancy BMI, GWG and EWG, fasting, 1-h and 2-h blood glucose values after the $75 \mathrm{~g}$ oGTT, HbA1c at the 1st booking after GDM diagnosis and at the end of the pregnancy, and maternal medical treatment requirement. Of note, correlation between prepregnancy BMI and BMI at the 1st booking after GDM diagnosis was very high $(r=0.93)$ and results unchanged when the latter was used for analysis. The pregnancy outcomes were all binary variables and included cesarean section, macrosomia, LGA, SGA, 
hypoglycemia, prematurity, hospitalization in the neonatal unit, and Apgar score at $5 \mathrm{~min}<7$.

\section{Statistical analysis}

All data were analyzed using Stata/SE 15.0 (StataCorp LLC, TX, USA). Normality of continuous variables was assessed, and normally distributed continuous variables were described as means and standard deviations (SDs). Binary outcomes were described as percentages.

Univariate logistic regression analyses, adjusting for gestational age at birth, neonatal sex and maternal age, were initially conducted. Due to the small number of some neonatal complications, analysis was only performed for adverse outcomes present in more than 20 cases [37]. Therefore, the following outcomes were removed from further analysis: 5-min Apgar score $<7$, stillbirth and death.

Maternal predictors of adverse neonatal outcomes with a $p$-value $<0.2$ in the univariate analysis were included in the stepwise multiple logistic regression analysis model. This analysis was also adjusted for gestational age at birth, neonatal gender and maternal age, and was conducted in order to identify the maternal anthropometric and metabolic predictors that are most significantly associated with adverse neonatal and maternal outcomes. Due to the strong correlation between HbA1c at the 1st booking and at the end of pregnancy $(r=0.73)$, two separate multiple regression models were selected when these two predictors had a $p$-value $<0.2$ in the univariate analysis for the same outcome. Women were then divided in 2 groups depending on their HbA1C value at the 1st booking (HbA1c < 5.5 (37 $\mathrm{mmol} / \mathrm{mol})$ and $\mathrm{HbA} 1 \mathrm{c} \geq 5.5(37 \mathrm{mmol} / \mathrm{mol}))$ [38]. The cutoff value used corresponded to the median HbA1c value both at the 1st GDM booking and the end of pregnancy. Comparisons between the groups were initially made using the unpaired $t$-test for continuous variables and the Fischer's exact test for binary variables. Thereafter, the multiple regression analysis selected above was performed in both stratified groups. Probability analyses according to logistic regression models were used to evaluate the risk of the 2 most frequent outcomes, i.e. cesarean section and LGA based on 2 correlates that are routinely and easily available at the 1st GDM booking: prepregnancy BMI and HbA1c at 1st GDM booking. For all analyses, adjusted odds ratios (aORs) are reported along with their $95 \%$ confidence intervals $(\mathrm{CI})$, and statistical significance was defined at the two-sided $\alpha$ level of 0.05 , unless specified otherwise.

\section{Results}

\section{Study population description}

Out of a population of 851 adult women, 111 women were excluded because they did not provide an informed consent, 5 due to a known type 1 and 8 due to known type 2 diabetes. Twelve women were excluded due to a suspicion of preexistent diabetes, and 9 because they participated in an intervention clinical trial. Finally, 130 women were excluded due to multiple gestation, missing newborn sex and/or birth weight. Overall, 576 women were included in the final analysis.

Baseline maternal characteristics are shown in Table 1. Mean maternal age was $32.8 \pm 5.5$ years. Fifty $\%$ of the women were either overweight or obese before pregnancy. Mean gestational age at GDM diagnosis was 28.6 weeks $(\mathrm{SD} \pm 3.3)$. Thirty-nine $\%$ women were part of a high-risk ethnic group. Mean gestational weight gain in the cohort was $12.7 \mathrm{~kg}(\mathrm{SD} \pm 6.2)$, with most of the weight gain taking place before the 1st booking $(10.3 \mathrm{~kg}(\mathrm{SD} \pm 5.6 \mathrm{~kg})$ vs $2.5(\mathrm{SD} \pm 2.7 \mathrm{~kg})$ after $)$. Gestational weight gain exceeded the Institute of Medicine recommendations in $30 \%$ of the patients. Mean $\mathrm{HbA1c}$ value was $5.5 \%(37 \mathrm{mmol} / \mathrm{mol}), \quad \mathrm{SD} \pm 0.4 \%(5 \mathrm{mmol} /$ $\mathrm{mol})$ at the 1 st booking and $5.6 \%(38 \mathrm{mmol} / \mathrm{mol}), \mathrm{SD} \pm$ $0.4 \%(5 \mathrm{mmol} / \mathrm{mol})$ at the end of pregnancy, while median values were the same at both time points $(5.5 \%$ $(37 \mathrm{mmol} / \mathrm{mol}))$. A medical treatment was required in $58 \%$ of the women; $8 \%$ were treated with metformin only and $50 \%$ required insulin $(3.3 \%$ in combination with metformin). Cesarean section, including planed and emergency cesarean section, was performed in 38\% of the population.

Regarding the neonatal characteristics and outcomes (see Table 1), mean gestational age at birth was 38.9 weeks $(\mathrm{SD} \pm 1.9)$. Macrosomia was present in $7.8 \%$, LGA in $16.5 \%$ and SGA in $9.4 \%$ of newborns. Hypoglycemia occurred in $10.7 \%$ and prematurity in $8.2 \%$ of newborns. Admission in the neonatal unit was required in $11.6 \%$ of cases. Jaundice requiring phototherapy was observed in $3.7 \%$ of the neonatal population and 5-min Apgar score $<7$ in $1.7 \%$. Stillbirth was seen in 2 fetuses, of whom one was excluded from the study due to missing sex and weight data. One newborn died after birth.

\section{Associations between predictors and neonatal and maternal outcomes}

The results of the univariate and multiple regression analyses are shown in Table 2 (univariate analyses, only those with $p<0.2$. The integral table with all variables is shown in Additional file 1: Table S1) and Table 3 (multiple regression analyses, only those with $p<0.05$. The integral table with all variables is shown in Additional file 2: Table S2).

We found the following results in the multiple regression analyses: prepregnancy BMI was positively associated with cesarean section requirement $(p=0.022)$ and inversely with SGA $(p=0.038)$. Higher GWG was associated with macrosomia and LGA (all $p \leq 0.001$ ). The 
Table 1 Descriptive maternal and neonatal characteristics

\begin{tabular}{|c|c|}
\hline \multicolumn{2}{|l|}{ Maternal characteristics } \\
\hline Age (years) & $32.8 \pm 5.5$ \\
\hline Prepregnancy BMI $\left(\mathrm{kg} / \mathrm{m}^{2}\right)$ & $26.1 \pm 5.4$ \\
\hline BMI at the $1 \mathrm{st}$ GDM booking $\left(\mathrm{kg} / \mathrm{m}^{2}\right)$ & $30 \pm 5.5$ \\
\hline Gestational weight gain (kg) & $12.7 \pm 6.2$ \\
\hline Gestational weight gain until the 1st GDM booking $(\mathrm{kg})$ & $10.3 \pm 5.6$ \\
\hline Excessive gestational weight gain ${ }^{a} n(\%)$ & $172(30)$ \\
\hline Fasting oGTT glucose value (mmol/l) & $5.2 \pm 0.8$ \\
\hline 1-h oGTT glucose value (mmol/l) & $9.6 \pm 2.0$ \\
\hline 2-h oGTT glucose value (mmol/l) & $7.8 \pm 1.9$ \\
\hline Gestational age at the 1st GDM booking (weeks) & $28.6 \pm 3.3$ \\
\hline $\mathrm{HbA} 1 \mathrm{c}$ at the 1 st GDM booking (\%) & $5.5 \pm 0.4$ \\
\hline$(\mathrm{mmol} / \mathrm{mol})$ & $37 \pm 5$ \\
\hline Gestational age at the end of pregnancy ${ }^{\mathrm{b}}$ (weeks) & $35.8 \pm 2.9$ \\
\hline $\mathrm{HbA} 1 \mathrm{c}$ at the end of pregnancy ${ }^{\mathrm{b}}(\%)$ & $5.6 \pm 0.4$ \\
\hline$(\mathrm{mmol} / \mathrm{mol})$ & $38 \pm 5.0$ \\
\hline High risk ethnicity n(\%) & $219(39)$ \\
\hline Cesarean section n(\%) & $212(38)$ \\
\hline Maternal medical treatment requirement n(\%) & $297(58)$ \\
\hline \multicolumn{2}{|l|}{ Neonatal characteristics } \\
\hline Gestational age (weeks) & $38.9 \pm 1.9$ \\
\hline Male n(\%) & $297(52)$ \\
\hline $\mathrm{LGA}^{\mathrm{c}} \mathrm{n}(\%)$ & $95(16.5)$ \\
\hline$S G A^{d} n(\%)$ & $54(9.4)$ \\
\hline Macrosomia ${ }^{e}(\%)$ & $45(7.8)$ \\
\hline Hypoglycemia $^{f} n(\%)$ & $56(10.7)$ \\
\hline Prematurity ${ }^{9}$ (\%) & $47(8.2)$ \\
\hline Hospitalization for neonatal complication n(\%) & $61(11.6)$ \\
\hline Jaundice requiring phototherapy n(\%) & $21(3.7)$ \\
\hline Apgar 5-min < $7 \mathrm{n}(\%)$ & $10(1.7)$ \\
\hline
\end{tabular}

Abbreviations: BMI Body mass index, GDM Gestational diabetes mellitus, oGTT Oral glucose tolerance test, HbA1c Glycated hemoglobin, LGA Large for gestational age, SGA Small for gestational age

a according to the Institute of Medicine guidelines [13]

${ }^{b}$ this corresponds to the last visit at the GDM clinic

c LGA: birth weight > 90th percentile for sex and gestational age using the Intergrowth 21st newborn size application tool [30]

d SGA: birth weight $<10$ th percentile for sex and gestational age using the

Intergrowth 21st newborn size application tool [30]

e birth weight $\geq 4000 \mathrm{~g}$

${ }^{\mathrm{f}}$ capillary or venous glucose value $\leq 2.5 \mathrm{mmol} / \mathrm{l}$

${ }^{g}$ gestational age $<37$ weeks

1-h oGTT glucose value predicted cesarean section requirement $(p=0.024)$, but otherwise there was no significant association between oGTT values and adverse outcomes. Importantly, HbA1c at the 1st booking was positively associated with macrosomia, LGA and the need for cesarean section in the univariate analysis (all $p<0.05$ ); however, it did not display any significant associations with neonatal or maternal outcomes in the multiple regression models. HbA1c at the end of pregnancy was also associated with macrosomia, LGA and prematurity in the multiple regression analyses (all $p<$ 0.05 ). Finally, maternal treatment requirement was associated with a two-fold higher risk of neonatal hypoglycemia $(p=0.032)$.

No maternal predictor showed a significant association with hospitalization for neonatal complications and jaundice requiring phototherapy in the multiple regression analyses.

\section{HbA1c stratification}

Women participating in this study were further stratified in 2 groups, according to the median HbA1c value at the 1st GDM booking and at the end of pregnancy $(<5.5 \%$ vs $\geq 5.5 \%(37 \mathrm{mmol} / \mathrm{mol})$. Regarding maternal characteristics, there were significant differences in age, anthropometric and metabolic parameters, high risk ethnicity, cesarean section and medical treatment requirement, when stratifying by $\mathrm{HbA} 1 \mathrm{c}$ at 1 st GDM booking (See Additional file 3: Table S3). On the other side, few differences in maternal characteristics were found when stratifying by the same HbAlc at the end of pregnancy. Regarding neonatal outcomes, no significant differences were observed when stratifying by HbA1c at the 1st GDM booking, while for HbA1c at the end of pregnancy macrosomia, prematurity and jaundice requiring phototherapy were significantly more prevalent (all $p<0.05$ ).

The results of the multiple regression analyses are shown in the Table 4. In women with HbA1c $\geq 5.5 \%$ (37 $\mathrm{mmol} / \mathrm{mol}$ ) at 1st GDM booking and at the end of pregnancy, GWG was associated with more macrosomia and LGA (all $p \leq 0.03$ ). In women with $\mathrm{HbA1c} \geq 5.5 \%$ (37 $\mathrm{mmol} / \mathrm{mol}$ ) at the 1st GDM booking, higher prepregnancy BMI was associated with the need for a cesarean section and higher 1-h oGTT glucose values with prematurity (both $\mathrm{p} \leq 0.03$ ). In women with an HbA1c $\geq$ $5.5 \%(37 \mathrm{mmol} / \mathrm{mol})$ at the end of pregnancy, maternal medical treatment requirement was associated with more hypoglycemia $(p=0.020)$ and less SGA $(p=0.044)$ and prepregnancy BMI was also associated with less SGA $(p=0.028)$. On the other hand, no association was found between maternal predictors and neonatal and maternal complications in the group of women with $\mathrm{HbA} 1 \mathrm{c}<5.5 \%(37 \mathrm{mmol} / \mathrm{mol})$, neither at the 1 st GDM booking nor at the end of the pregnancy.

\section{Risk stratification at the $1^{\text {st }} \mathrm{GDM}$ booking}

Finally, probability analyses according to logistic regression models were performed to provide a risk stratification for the 2 most frequent adverse outcomes, i.e. cesarean section and LGA according to the prepregnancy BMI $(<25 \mathrm{vs} \geq 25 \mathrm{~kg} / \mathrm{m} 2)$ and HbA1c $(<5.5$ vs $\geq$ 
Table 2 Maternal predictors of adverse neonatal and maternal outcomes in univariate analysis

\begin{tabular}{|c|c|c|c|c|c|}
\hline \multirow{2}{*}{$\begin{array}{l}\text { Presence of neonatal and maternal outcomes } \\
\text { Cesarean section }\end{array}$} & \multirow{2}{*}{$\frac{\text { Maternal predictors }}{\text { Prepregnancy BMI }\left(\mathrm{kg} / \mathrm{m}^{2}\right)}$} & \multirow{2}{*}{$\frac{\text { Odds Ratio }}{1.06}$} & \multicolumn{2}{|c|}{$95 \% \mathrm{Cl}$} & \multirow{2}{*}{$\frac{P \text {-value }}{0.001}$} \\
\hline & & & 1.02 & 1.09 & \\
\hline & Excess weight gain ${ }^{a}$ & 1.18 & 1.00 & 1.38 & 0.048 \\
\hline & 1-h oGTT glucose (mmol/l) & 1.10 & 0.99 & 1.23 & 0.084 \\
\hline & 2-h oGTT glucose (mmol/l) & 1.08 & 0.97 & 1.20 & 0.166 \\
\hline & $\mathrm{HbA} 1 \mathrm{c}$ at the 1 st GDM booking $(\% / \mathrm{mmol} / \mathrm{mol})$ & 1.63 & 1.04 & 2.56 & 0.033 \\
\hline & Maternal medical treatment requirement & 1.65 & 1.11 & 2.44 & 0.013 \\
\hline \multirow[t]{8}{*}{ Macrosomia $^{b}$} & Gestational weight gain (kg) & 1.11 & 1.05 & 1.17 & $<0.001$ \\
\hline & Excess weight gain) ${ }^{a}$ & 1.41 & 1.10 & 1.79 & 0.006 \\
\hline & Fasting oGTT glucose (mmol/l) & 1.63 & 1.16 & 2.29 & 0.005 \\
\hline & 1-h oGTT glucose (mmol/l) & 1.17 & 0.96 & 1.42 & 0.115 \\
\hline & 2-h oGTT glucose (mmol/l) & 1.21 & 0.99 & 1.47 & 0.065 \\
\hline & HbA1c at the 1 st GDM booking $(\% / \mathrm{mmol} / \mathrm{mol})$ & 2.92 & 1.42 & 6.03 & 0.004 \\
\hline & $\mathrm{HbA} 1 \mathrm{c}$ at the end of pregnancy $(\% / \mathrm{mmol} / \mathrm{mol})^{c}$ & 6.45 & 1.82 & 22.90 & 0.004 \\
\hline & Maternal medical treatment requirement & 2.75 & 1.29 & 5.86 & 0.009 \\
\hline \multirow[t]{8}{*}{$L_{G} A^{d}$} & Prepregnancy BMI (kg/m²) & 1.04 & 1.00 & 1.08 & 0.064 \\
\hline & Gestational weight gain (kg) & 1.08 & 1.04 & 1.12 & $<0.001$ \\
\hline & Excess weight gain ${ }^{a}$ & 1.46 & 1.23 & 1.74 & $<0.001$ \\
\hline & Fasting oGTT glucose (mmol/l) & 1.46 & 1.12 & 1.91 & 0.006 \\
\hline & 1-h oGGT glucose $(\mathrm{mmol} / \mathrm{l})$ & 1.13 & 0.99 & 1.29 & 0.077 \\
\hline & HbA1c at the 1st GDM booking $(\% / \mathrm{mmol} / \mathrm{mol})$ & 1.84 & 1.08 & 3.14 & 0.025 \\
\hline & $\mathrm{HbA} 1 \mathrm{c}$ at the end of pregnancy $(\% / \mathrm{mmol} / \mathrm{mol})^{c}$ & 2.84 & 1.01 & 7.93 & 0.047 \\
\hline & Maternal medical treatment requirement & 1.91 & 1.14 & 3.20 & 0.014 \\
\hline \multirow[t]{2}{*}{$S G A^{e}$} & Prepregnancy BMI (kg/m²) & 0.95 & 0.81 & 1.00 & 0.077 \\
\hline & Maternal medical treatment requirement & 0.59 & 0.32 & 1.08 & 0.087 \\
\hline \multirow[t]{2}{*}{ Hypoglycemia $^{f}$} & Excess weight gain ${ }^{a}$ & 1.20 & 0.96 & 1.50 & 0.107 \\
\hline & Maternal medical treatment requirement & 2.03 & 1.06 & 3.88 & 0.032 \\
\hline \multirow[t]{3}{*}{ Prematurity $^{9}$} & Gestational weight gain (kg) & 0.97 & 0.94 & 1.01 & 0.159 \\
\hline & 1-h oGTT glucose (mmol/l) & 1.13 & 0.94 & 1.36 & 0.188 \\
\hline & $\mathrm{HbA} 1 \mathrm{c}$ at the end of pregnancy $(\% / \mathrm{mmol} / \mathrm{mol})^{c}$ & 12.48 & 1.85 & 84.13 & 0.010 \\
\hline Hospitalization for neonatal complication & Gestational weight gain (kg) & 0.97 & 0.93 & 1.00 & 0.082 \\
\hline \multirow[t]{2}{*}{ Jaundice requiring phototherapy } & Prepregnancy BMI (kg/m²) & 1.08 & 0.99 & 1.18 & 0.071 \\
\hline & Excess weight gain ${ }^{a}$ & 1.31 & 0.89 & 1.95 & 0.174 \\
\hline \multicolumn{6}{|c|}{$\begin{array}{l}\text { Univariate logistic regression analyses adjusted for maternal age, neonatal sex and gestational age. This table shows the odds ra } \\
\text { of adverse neonatal and maternal outcomes. Only variables with a p-value of }<0.2 \text { are displayed. See Additional file } 1: \text { Table } S 1 \\
\text { Abbreviations: CI Confidence interval, BMI Body mass index, GDM Gestational diabetes mellitus, OGTT Oral glucose tolerance test, } \\
\text { Large for gestational age, SGA Small for gestational age } \\
\text { a according to the Institute of Medicine } 2009 \text { guidelines [13] } \\
\text { b birth weight } \geq 4000 \mathrm{~g} \\
\text { c this corresponds to the last visit at the GDM clinic } \\
\text { d LGA: birth weight }>90 \text { th percentile for sex and gestational age using the Intergrowth } 21 \text { st newborn size application tool [30] } \\
\text { e SGA: birth weight }<10 \text { th percentile for sex and gestational age using the Intergrowth } 21 \text { st newborn size application tool [30] } \\
\text { f capillary or venous glucose value } \leq 2.5 \mathrm{mmol} / / \\
{ }^{g} \text { gestational age }<37 \text { weeks }\end{array}$} \\
\hline
\end{tabular}

$5.5 \%(37 \mathrm{mmol} / \mathrm{mol}))$. These predictors can be easily assessed at the 1st GDM booking (Table 5) and were significant in the univariate analyses. In the lowest risk category $(\mathrm{BMI}<25 \mathrm{~kg} / \mathrm{m} 2$ and $\mathrm{HbA} 1 \mathrm{c}<5.5 \%)$, the probability for cesarean section was $27 \%$ (similar to the rate of cesarean section in our tertiary hospital (CHUV) which is $29 \%$ [39]) and LGA was $12 \%$, while this risk was 1.8 times higher (48\%) for cesarean section and 1.9 times higher (23\%) for LGA in the highest risk category. 
Table 3 Maternal predictors of adverse neonatal and maternal outcomes in stepwise multiple logistic regression analysis

\begin{tabular}{|c|c|c|c|c|}
\hline & Odds Ratio & $95 \% C$ & & $P$-value \\
\hline \multicolumn{5}{|c|}{ Cesarean section } \\
\hline 1-h oGTT-glucose (mmol/l) & 1.15 & 1.02 & 1.29 & 0.024 \\
\hline Prepregnancy BMI (kg/m²) & 1.05 & 1.01 & 1.09 & 0.022 \\
\hline \multicolumn{5}{|c|}{ Macrosomia $^{a}$} \\
\hline Gestational weight gain (kg) & 1.11 & 1.05 & 1.19 & 0.001 \\
\hline $\mathrm{HbA} 1 \mathrm{c}$ at the end of pregnancy $(\% / \mathrm{mmol} / \mathrm{mol})$ & 6.84 & 1.53 & 30.54 & 0.012 \\
\hline \multicolumn{5}{|c|}{$\operatorname{LGA}^{c}$} \\
\hline Gestational weight gain (kg) & 1.11 & 1.06 & 1.17 & $<0.001$ \\
\hline $\mathrm{HbA} 1 \mathrm{c}$ at the end of pregnancy ${ }^{c}(\% / \mathrm{mmol} / \mathrm{mol})$ & 4.68 & 1.27 & 17.28 & 0.021 \\
\hline \multicolumn{5}{|c|}{$S G A^{d}$} \\
\hline Prepregnancy BMI $\left(\mathrm{kg} / \mathrm{m}^{2}\right)$ & 0.93 & 0.88 & 0.99 & 0.038 \\
\hline \multicolumn{5}{|c|}{ Hypoglycemia $^{e}$} \\
\hline Maternal medical treatment requirement & 2.03 & 1.06 & 3.88 & 0.032 \\
\hline \multicolumn{5}{|c|}{ Prematurity $^{\mathrm{f}}$} \\
\hline $\mathrm{HbA} 1 \mathrm{c}$ at the end of pregnancy ${ }^{\mathrm{c}}(\% / \mathrm{mmol} / \mathrm{mol})$ & 22.4 & 2.36 & 213.2 & 0.007 \\
\hline \multicolumn{5}{|c|}{$\begin{array}{l}\text { Stepwise multiple logistic regression analyses with all the variables presented in Table 2, adjusted for maternal age, neonatal se } \\
\text { are only shown if at least one predictor is found. Only significant results are displayed (defined significance, } P<0.05 \text {, see text). } \\
\text { all results } \\
\text { Abbreviations: } C \text { C Confidence interval, BMI Body mass index, GDM Gestational diabetes mellitus, oGTा Oral glucose tolerance tes } \\
\text { Large for gestational age, SGA Small for gestational age } \\
\text { a birth weight } \geq 4000 \mathrm{~g} \\
\text { b this corresponds to the last visit at the GDM clinic } \\
\text { c LGA: birth weight }>90 \text { th percentile for sex and gestational age using the Intergrowth } 21 \text { st newborn size application tool [6] } \\
\text { d SGA: birth weight }<10 \text { th percentile for sex and gestational age using the Intergrowth } 21 \text { st newborn size application tool [6] } \\
\text { e capillary or venous glucose value } \leq 2.5 \mathrm{mmol} / \mathrm{l} \\
\text { f gestational age }<37 \text { weeks }\end{array}$} \\
\hline
\end{tabular}

\section{Discussion}

In this study of 576 singleton pregnancies in multiethnic women with GDM, the following potentially modifiable anthropometric and metabolic parameters were shown to be important predictors of adverse neonatal and/or maternal outcomes (cesarean section, macrosomia, LGA, SGA, hypoglycemia, prematurity) in the multiple regression analyses: prepregnancy BMI, GWG, HbA1c at the end of pregnancy, 1-h oGTT glucose values at GDM diagnosis, and maternal medical treatment requirement. In the presence of GWG, EWG was not associated with adverse neonatal outcomes which hints to the superiority of GWG to predict these outcomes. In terms of future potential clinical risk stratification, the present study also revealed that in the context of a treated population of women with GDM, associations between anthropometric and metabolic parameters and complications are exclusively observed in women with $\mathrm{HbA} 1 \mathrm{c} \geq 5.5 \%(37 \mathrm{mmol} / \mathrm{mol})$. Another risk stratification model showed that in women with a prepregnancy BMI of $\geq 25 \mathrm{~kg} / \mathrm{m}^{2}$ and a HbA1c $\geq 5.5 \%$ (37 $\mathrm{mmol} / \mathrm{mol}$ ) at the 1st GDM booking, the risk for the two most frequent adverse outcomes, i.e. cesarean section and LGA were around nearly twice as high compared to women with a BMI of $<25 \mathrm{~kg} / \mathrm{m}^{2}$ and a HbAlc $<5.5 \%(37 \mathrm{mmol} / \mathrm{mol})$.

Prepregnancy BMI was significantly correlated with the need for cesarean section, which is also consistent with previous studies [40, 41]. It showed an inverse association with SGA in univariate and multiple regression analyses, in good agreement with a metanalysis by Goto et al. and a study by Li et al. [42, 43]. Prepregnancy BMI was associated with LGA in univariate analyses, but these associations did not remain significant in the multiple regression model. This indicates that other correlates, specifically GWG and metabolic control in the 3rd trimester, reflected by the HbA1c at the end of pregnancy, may have a more potent influence on fetal growth. A previous study demonstrated a higher risk for macrosomia and LGA in overweight and obese patients; however these studies did not use a multiple regression model including also the 3rd trimester metabolic control 
Table 4 Maternal predictors of neonatal and maternal outcomes in multiple logistic regression analysis stratified by median HbA1c values

\begin{tabular}{|c|c|c|c|c|c|c|c|c|c|}
\hline & & Odds Ratio & \multicolumn{2}{|c|}{$95 \% \mathrm{Cl}$} & $P$-value & Odds Ratio & \multicolumn{2}{|c|}{$95 \% \mathrm{Cl}$} & $P$-value \\
\hline & & \multicolumn{4}{|c|}{$\begin{array}{l}\mathrm{HbA} 1 \mathrm{c} \text { at the } 1 \mathrm{st} \text { GDM booking } \geq 5.5 \% \text { (37 } \\
\mathrm{mmol} / \mathrm{mol} \text { ) }\end{array}$} & \multicolumn{4}{|c|}{$\begin{array}{l}\mathrm{HbA1c} \text { at the } 1 \mathrm{st} \text { GDM booking }<5.5 \% \text { (37 } \\
\mathrm{mmol} / \mathrm{mol} \text { ) }\end{array}$} \\
\hline Cesarean section & Prepregnancy BMI (kg/m²) & 1.07 & 1.01 & 1.15 & 0.031 & 1.02 & 0.96 & 1.09 & 0.545 \\
\hline Macrosomia $^{a}$ & Gestational weight gain (kg) & 1.19 & 1.06 & 1.33 & 0.003 & 0.99 & 0.85 & 1.14 & 0.846 \\
\hline$L_{G} A^{b}$ & Gestational weight gain (kg) & 1.17 & 1.07 & 1.30 & 0.001 & 0.99 & 0.88 & 1.11 & 0.813 \\
\hline \multirow[t]{2}{*}{ Prematurity $^{d}$} & 1-h oGTT glucose value $(\mathrm{mmol} / \mathrm{l})$ & 1.37 & 1.03 & 1.81 & 0.030 & 1.10 & 0.77 & 1.58 & 0.590 \\
\hline & & \multicolumn{4}{|c|}{$\begin{array}{l}\mathrm{HbA} 1 \mathrm{c} \text { at the end of pregnancy } \geq 5.5 \% \\
(37 \mathrm{mmol} / \mathrm{mol})^{\mathrm{e}}\end{array}$} & \multicolumn{4}{|c|}{$\begin{array}{l}\mathrm{HbA} 1 \mathrm{c} \text { at the end of pregnancy }<5.5 \%(37 \\
\mathrm{mmol} / \mathrm{mol})^{\mathrm{e}}\end{array}$} \\
\hline Macrosomia $^{a}$ & Gestational weight gain $(\mathrm{kg})$ & 1.11 & 1.02 & 1.21 & 0.013 & $-^{f}$ & $-{ }^{f}$ & $-^{f}$ & $-f^{f}$ \\
\hline$L G A^{b}$ & Gestational weight gain (kg) & 1.09 & 1.02 & 1.17 & 0.009 & 1.25 & 0.47 & 3.29 & 0.658 \\
\hline \multirow[t]{2}{*}{$S G A^{c}$} & Prepregnancy BMI (kg/m²) & 0.92 & 0.86 & 0.99 & 0.028 & 1.06 & 0.88 & 1.26 & 0.547 \\
\hline & Maternal medical treatment requirement & 0.50 & 0.26 & 0.98 & 0.044 & 3.26 & 0.43 & 24.75 & 0.254 \\
\hline Hypoglycemia $^{9}$ & Maternal medical treatment requirement & 2.52 & 1.16 & 5.48 & 0.020 & 0.95 & 0.23 & 3.91 & 0.944 \\
\hline
\end{tabular}

Multiple logistic regression analyses with all the variables presented in Table 2, adjusted for maternal age, neonatal sex and gestational age. Median $\mathrm{HbA1c}$ values are used for stratification. Predictors are only shown if the $P$ value is $<0.05$ in the multiple regression analysis in either stratified group. Outcomes are only shown if at least one predictor is found

Abbreviations: HbA1c Glycated hemoglobin, CI Confidence interval, GDM Gestational diabetes mellitus, BMI Body mass index, oGTT Oral glucose tolerance test, $L G A$ Large for gestational age, SGA Small for gestational age

${ }^{\text {a }}$ birth weight $\geq 4000 \mathrm{~g}$

${ }^{b}$ LGA: birth weight $>90$ th percentile for sex and gestational age using the Intergrowth 21st newborn size application tool [30]

c SGA: birth weight < 10th percentile for sex and gestational age using the Intergrowth 21st newborn size application tool [30]

d gestational age $<37$ weeks

e this corresponds to the last visit at the GDM clinic

${ }^{f}$ statistical analysis not possible due to the small amount of outcomes

${ }^{\mathrm{g}}$ capillary or venous glucose value $\leq 2.5 \mathrm{mmol} / \mathrm{l}$

[44]. In accordance with our data, a recent work showed that maternal overweight and obesity are not independent determinants of increased birth weight, in contrast to 3rd trimester glycemic control [21]. Further studies are necessary to elucidate this observation.

GWG was a significant predictor of LGA and macrosomia in both univariate and multiple regression analyses. This is in accordance with previous studies, which demonstrate a direct association between maternal weight gain during pregnancy and offspring birthweight [12, 45-48]. Importantly, in our population most of the weight was gained before the 1st visit at the GDM clinic which occurred at a mean of 29 weeks of GA $(10.3 \pm 5.6$ vs $2.5 \pm 2.7 \mathrm{~kg}$ after). This points out the importance for GWG monitoring early in pregnancy, as rapid weight gain in early pregnancy may be associated with the risk of offspring complications. Although EWG showed a significant association with LGA and macrosomia in univariate analyses, these associations did not remain significant in the multiple regression model, suggesting that absolute GWG may influence fetal weight gain more decidedly. EGW was shown to be a significant predictor of LGA and macrosomia in former studies [14, $44,49,50]$, but these studies did not include GWG in their model.

In the multiple regression model, the 1-h oGTT glucose value predicted the need for cesarean section. There were no other significant associations between oGTT values and neonatal or maternal complications in this treated population. Similarly, a recent study by Ott et al., also found that glucose value at oGTT was not correlated with birth outcomes in treated populations, with few exceptions [21]. These findings are in contrast with the large-scale Hyperglycemia and adverse

Table 5 Probabilities of future cesarean section and LGA depending on prepregnancy BMI and HbA1c at the 1st GDM booking, according to logistic regression models

\begin{tabular}{llll}
\hline Prepregnancy BMI $\left(\mathrm{kg} / \mathrm{m}^{2}\right)$ & $\mathrm{HbA1c}$ at the 1 st GDM booking $(\% / \mathrm{mmol} / \mathrm{mol}))$ & Cesarean section $^{\mathrm{LGA}}$ \\
\hline$<25$ & $<5.5 / 37$ & $27 \%$ & $12 \%$ \\
$<25$ & $\geq 5.5 / 37$ & $36 \%$ & $14 \%$ \\
$\geq 25$ & $<5.5 / 37$ & $38 \%$ & $20 \%$ \\
$\geq 25$ & $\geq 5.5 / 37$ & $48 \%$ & $23 \%$
\end{tabular}

Abbreviations: LGA Large for gestational age, BMI Body mass index, HbA1c Glycated hemoglobin, GDM Gestational diabetes mellitus

${ }^{a}$ birth weight $>90$ th percentile for sex and gestational age using the Intergrowth 21 st newborn size application tool [30] 
pregnancy outcome study (HAPO) study [26] that showed a continuous association between maternal glucose values at the oGTT and fetal overgrowth in an untreated population. The discrepancy in our results may be due to the treatment's intensity and efficacy in the setting of a clinical follow-up.

Moreover, newborns whose mothers required medical treatment presented hypoglycemia twice as often, despite the rigorous feeding protocol. In contrast, in a recent Atlantic DIP study there was no difference in hypoglycemia rates in newborns of patients with GDM treated with insulin vs medical nutritional care [28]. The higher occurrence of neonatal hypoglycemia in the context of a maternal treatment may imply a worse glycemic control, but also higher variability and glucose peaks in these patients, which is not always captured by capillary glycemia and the HbA1c. To the best of our knowledge, this is a novel observation. A possible bias in this observation may be linked to the more frequent glucose monitoring in the newborns whose mothers required a medical treatment.

In the multiple regression analyses, HbA1c at the 1st GDM booking did not reveal any association with neonatal and maternal outcomes, in good agreement with previous studies $[17,18,51,52]$. This finding could be attributed to the fact that $\mathrm{HbA1c}$ reflects the metabolic control of the preceding weeks to months which is less relevant at around 29 weeks of gestational age. It is also explicable to the subsequent treatment's efficacy and metabolic control. Nevertheless, HbA1c at 1st GDM booking was associated with several outcomes in univariate analyses (cesarean section, macrosomia, LGA). Furthermore, when HbA1c at the 1 st GDM visit was $<5.5 \%$, there were no significant correlations between predictors and adverse outcomes. We also showed that HbA1c is useful for the stratification of the risk of LGA and cesarean section at the 1st GDM booking.

By contrast, HbA1c at the end of pregnancy was a powerful predictor of preterm birth, macrosomia and LGA in the multiple regression analyses. The HbA1c at the end of pregnancy value reflects the glycemic control during the weeks before birth, which is a period of rapid fetal weight gain. Few studies have evaluated the correlation between 3rd trimester $\mathrm{HbAlc}$ and anthropometric parameters as well as neonatal outcomes. Barquiel et al. showed that 3rd trimester HbA1c $>5 \%$ (31 $\mathrm{mmol} / \mathrm{mol}$ ) increases the risk of LGA and other neonatal complications [22]. Mikkelsen et al. found that in women with GDM, HbA1c $>5.6 \%(38 \mathrm{mmol} / \mathrm{mol})$ is associated with a threefold increase of LGA and sixfold increase of neonatal hypoglycemia. Gandhi et al. demonstrated a higher mean birth weight in newborns of women with GDM with a 3rd trimester HbA1c > $6.5 \%(48 \mathrm{mmol} / \mathrm{mol})$ [24]. To the best of our knowledge, this is the first study that discovered an association between $\mathrm{HbA} 1 \mathrm{c}$ at the end of pregnancy and prematurity. Tight 3rd trimester glycemia control seems to be a key target for avoiding neonatal complications in pregnancies with GDM.

We conducted a risk stratification model based on the median HbA1c values at 1st GDM booking and at the end of pregnancy (cut-off of $5.5 \%(37 \mathrm{mmol} / \mathrm{mol})$ for both). Regarding maternal characteristics, there were significant differences in anthropometric and metabolic parameters, high risk ethnicity, medical treatment requirement and cesarean section, when stratifying by HbA1c at 1 st booking $(<5.5 \%$ vs $\geq 5.5 \%(37 \mathrm{mmol} / \mathrm{mol}))$. Few differences were found when stratifying by HbA1c at the end of pregnancy. Regarding neonatal outcomes no significant differences were observed when stratifying by HbA1c at the 1st booking, while for HbA1c at the end of pregnancy macrosomia, prematurity and jaundice requiring phototherapy were more prevalent when HbA1c was $\geq 5.5 \%$ ( $37 \mathrm{mmol} / \mathrm{mol}$ ) (all $p<0.05)$. Of note, achieving an $\mathrm{HbAlc}$ of $<5.5 \%(37 \mathrm{mmol} / \mathrm{mol})$ needed many lifestyle advices and encouragement and in almost half of the women (46\%) also a medical treatment. We only have national Swiss data for cesarean section rates and prematurity: Comparing to these data, cesarean section rates in the subgroup with HbA1c $<5.5 \%(37 \mathrm{mmol} /$ $\mathrm{mol}$ ) at the 1st booking, were comparable to the general population ( $31 \%$ vs $29 \%$ ), but were higher for the other subgroups [39]. Prematurity was lower in the subgroup with $\mathrm{HbA} 1 \mathrm{c}<5.5 \%(37 \mathrm{mmol} / \mathrm{mol})$ at the end of the pregnancy compared to the general population $(1.2 \%$ vs 7\%) [53]. When comparing to international and mainly US data, macrosomia and jaundice requiring phototherapy were even similar in both HbA1c-subgroups [54, 55]. In the subgroup of $\mathrm{HbA} 1 \mathrm{c}<5.5 \%(37 \mathrm{mmol} / \mathrm{mol})$ at the end of pregnancy, hospitalization for neonatal complications was similar to international data [56, 57]. While it is encouraging to observe that many outcomes in this treated GDM population are close to the general population, it is important to note that ethnic and population differences as well as differences in the clinical settings also play a role.

Interestingly, the associations between maternal predictors and neonatal and maternal outcomes were exclusively seen when $\mathrm{HbA} 1 \mathrm{c}$ was $\geq 5.5 \%(37 \mathrm{mmol} / \mathrm{mol})$. This may highlight the need for a more rigorous followup in these women, and a tighter monitoring of their glucose values. In these women, a repeated HbA1c 1-2 months later could be discussed if capillary glucose values were normal. In cases where the $\mathrm{HbAlc}$ value remains high despite normal capillary values, continuous glucose monitoring could be proposed if occasional peaks or nocturnal glucose elevation are suspected. Further studies are necessary to evaluate whether HbAlc 
could be used for risk stratification of adverse neonatal and maternal outcomes in pregnancies complicated with GDM, and to determine an HbA1c threshold above which maternal or neonatal follow-up may need to be intensified.

Finally, we performed probability analyses according to logistic regression models for risk stratification at the 1st booking based on simple anthropometric and metabolic parameters, such as maternal prepregnancy BMI and HbA1c at the 1st booking using the two most frequent adverse outcomes (caesarean section and LGA). In the highest risk category (BMI of $\geq 25 \mathrm{~kg} / \mathrm{m}^{2}$ and a HbA1c $\geq 5.5 \%(37 \mathrm{mmol} / \mathrm{mol}))$, the probability was 1.8 times higher and 1.9 times higher for cesarean section and LGA respectively compared to the lowest category. We are not aware of other studies providing a risk stratification for these clinically relevant parameters.

The strengths of our study included its prospective nature, which ensured the presence of complete detailed information on maternal and neonatal characteristics, as well as several novel findings in the multiple regression analyses, the stratified analyses and the probability analyses. However, several limitations may also be noted. Firstly, HbA1c is subject to specific pregnancy changes, shows ethnic variation, and may be affected by conditions such as haemolytic anaemia, chronic renal failure, severe liver disease and anaemia of chronic disease, which might influence its validity [58]. HbA1c at the end of pregnancy was only documented after March 2015, leading to a smaller sample group for this predictor $(n=$ 201), which nevertheless did not limit its statistical significance. However, a higher sample size could have identified its predictive role for even more outcomes. A larger population would also have led to a higher number of rare outcomes and therefore would have ensured the possibility to include these outcomes in the multivariate models. Moreover, the indication for cesarean section was not specified. Dividing the population in cesarean section subgroups, such as elective or emergency could be interesting, but would lead to smaller population sizes and limited statistical power. Another limitation is that the prepregnancy BMI and the gestational weight gain were determined using the selfreported pre-pregnancy weight or data from the medical charts. A recent review study showed that the magnitude of error of the self-reported weight is small, and does not largely bias associations between pregnancy-related weight and birth outcomes [59]. In our study, prepregnancy BMI and BMI at the 1st booking after GDM diagnosis were highly correlated $(r=0.93)$. Identification of modifiable factors before GDM diagnosis or even before pregnancy would be essential to improve maternal and neonatal outcomes, but unfortunately we only have valid data for women after the diagnosis of GDM. Another limitation is that this is an explorative study. Its results can be used to create new hypotheses.

\section{Conclusions}

The present study demonstrated the important role of simple anthropometric and metabolic maternal predictors on the occurrence of adverse neonatal and maternal outcomes. We were able to identify several very important predictors: prepregnancy BMI, GWG, maternal treatment requirement and $\mathrm{HbA1c}$ at the end of pregnancy. We also found that predictors were exclusively associated to adverse neonatal and maternal outcomes when the $\mathrm{HbAlc}$ values were $\geq 5.5 \%(37 \mathrm{mmol} / \mathrm{mol})$ at the 1st GDM booking and/or at the end of the pregnancy. Risk stratification depending on the maternal prepregnancy BMI and $\mathrm{HbA1c}$ at the 1st GDM booking may allow for risk-adapted care in patients with GDM.

\section{Additional files}

Additional file 1: Table S1. (Supplementary to Table 2) - Maternal predictors of adverse neonatal and maternal outcomes in univariate analysis.

Additional file 2: Table S2. (Supplementary to Table 3) - Maternal predictors of adverse neonatal and maternal outcomes in stepwise multiple logistic regression analysis.

Additional file 3: Table S3. Comparisons between maternal and neonatal characteristics stratified by median $\mathrm{HbA} 1 \mathrm{c}$ values.

\begin{abstract}
Abbreviations
BMI: Body mass index; Cl: Confidence interval; DCCT: Diabetes control and complications trial; EGW: Excessive weight gain; GDM: Gestational diabetes mellitus; GWG: Gestational weight gain; HAPO: Hyperglycemia and adverse pregnancy outcome study; HbA1c: Glycated hemoglobin; HPLC: Highperformance liquid chromatography; ICU: Intensive care unit; IFCC: International federation of clinical chemistry and laboratory medicine; IOM: Institute of medicine; LGA: Large for gestational age; OGTT: Oral glucose tolerance test; SGA: Small for gestational age
\end{abstract}

\section{Acknowledgments}

None.

\section{Authors' contributions}

MCA participated in the conceptual design of the study, the data collection, analysis and interpretation and wrote the original draft. LG was involved in the study design, participated in the data collection and reviewed the final draft. JG participated in the data collection and reviewed the final draft. JBR participated in the data analysis and reviewed the final draft. CJFF contributed to the design and conceptualization of the study and revised the final draft. $\mathrm{V}$ contributed to the design and conceptualization of the study and revised the final draft. JJP was the coordinator of the study, participated in the conceptual design of the study, the data analysis and interpretation and corrected all drafts. All the authors critically reviewed the article for important intellectual content and approved the final version submitted for publication.

\section{Funding}

This study was sponsored by an unrestricted educational grant from NovoNordisk. The funding body did not take part in the design of the study, the collection, analysis, interpretation of data or in the writing of the manuscript. This study is a pilot of a project grant by the Swiss National Science Foundation (SNF 32003B_176119). 


\section{Availability of data and materials}

The databases used and analyzed are available from the corresponding author on reasonable request.

\section{Ethics approval and consent to participate}

Signed informed consent was obtained from all participating women. The study was conducted in accordance with the guidelines of the declaration of Helsinki, and good clinical practice. The Human Research Ethics Committee of the Canton de Vaud approved the study protocol (326/15).

\section{Consent for publication}

Not applicable.

\section{Competing interests}

The authors declare that they have no competing interests.

\section{Author details}

${ }^{1}$ Pediatric Service, Department Woman-Mother-Child, Lausanne University Hospital, Lausanne, Switzerland. 'Obstetric Service, Department Woman-Mother-Child, Lausanne University Hospital, Lausanne, Switzerland. ${ }^{3}$ Service of Endocrinology, Diabetes and Metabolism, Lausanne University Hospital, Lausanne, Switzerland.

Received: 30 March 2019 Accepted: 22 August 2019

Published online: 04 December 2019

\section{References}

1. Gestational diabetes mellitus. Diabetes Care. 2003;26(suppl 1):s103-s5. https://doi.org/10.2337/diacare.26.2007.S103.

2. Anna V, van der Ploeg HP, Cheung NW, Huxley RR, Bauman AE. Sociodemographic correlates of the increasing trend in prevalence of gestational diabetes mellitus in a large population of women between 1995 and 2005. Diabetes Care. 2008;31(12):2288-93. https://doi.org/10. 2337/dc08-1038.

3. Ferrara A. Increasing prevalence of gestational diabetes mellitus. A public health perspective. Diabetes Care. 2007;30(Supplement 2):S141-S6. https:// doi.org/10.2337/dc07-s206.

4. Ryser Ruetschi J, Jornayvaz FR, Rivest R, Huhn EA, Irion O, Boulvain M. Fasting glycaemia to simplify screening for gestational diabetes. BJOG. 2016; 123(13):2219-22. https://doi.org/10.1111/1471-0528.13857.

5. Mitanchez D, Yzydorczyk C, Siddeek B, Boubred F, Benahmed M, Simeoni U. The offspring of the diabetic mother--short- and long-term implications. Best Pract Res Clin Obstet Gynaecol. 2015;29(2):256-69. https://doi.org/10. 1016/j.bpobgyn.2014.08.004.

6. Mitanchez D, Yzydorczyk C, Simeoni U. What neonatal complications should the pediatrician be aware of in case of maternal gestational diabetes? World J Diabetes. 2015;6(5):734-43. https://doi.org/10.4239/wjd.v6.15.734.

7. Ovesen PG, Jensen DM, Damm P, Rasmussen S, Kesmodel US. Maternal and neonatal outcomes in pregnancies complicated by gestational diabetes. A nation-wide study. J Matern Fetal Neonatal Med. 2015;28(14):1720-4. https://doi.org/10.3109/14767058.2014.966677.

8. Crowther CA, Hiller JE, Moss JR, McPhee AJ, Jeffries WS, Robinson JS. Effect of treatment of gestational diabetes mellitus on pregnancy outcomes. $\mathrm{N}$ Engl J Med. 2005;352(24):2477-86. https://doi.org/10.1056/NEJMoa042973.

9. Landon MB, Spong CY, Thom E, Carpenter MW, Ramin SM, Casey B, et al. A multicenter, randomized trial of treatment for mild gestational diabetes. $\mathrm{N}$ Engl J Med. 2009;361(14):1339-48. https://doi.org/10.1056/NEJMoa0902430

10. Catalano PM, McIntyre HD, Cruickshank JK, McCance DR, Dyer AR, Metzger $\mathrm{BE}$, et al. The hyperglycemia and adverse pregnancy outcome study: associations of GDM and obesity with pregnancy outcomes. Diabetes Care 2012;35(4):780-6. https://doi.org/10.2337/dc11-1790.

11. Aune D, Saugstad OD, Henriksen T, Tonstad S. Maternal body mass index and the risk of fetal death, stillbirth, and infant death: a systematic review and meta-analysis. JAMA. 2014;311(15):1536-46. https://doi.org/10.1001/ jama.2014.2269.

12. Aiken CEM, Hone L, Murphy HR, Meek CL. Improving outcomes in gestational diabetes: does gestational weight gain matter? Diabet Med. 2018. https://doi.org/10.1111/dme.13767.

13. Rasmussen KM, Catalano PM, Yaktine AL. New guidelines for weight gain during pregnancy: what obstetrician/gynecologists should know. Curr Opin
Obstet Gynecol. 2009;21(6):521-6. https://doi.org/10.1097/GCO. ob013e328332d24e.

14. Truong YN, Yee LM, Caughey AB, Cheng YW. Weight gain in pregnancy: does the Institute of Medicine have it right? Am J Obstet Gynecol. 2015; 212(3):362.e1-8. https://doi.org/10.1016/j.ajog.2015.01.027.

15. Stotland NE, Cheng YW, Hopkins LM, Caughey AB. Gestational weight gain and adverse neonatal outcome among term infants. Obstet Gynecol. 2006; 108(3 Pt 1):635-43. https://doi.org/10.1097/01.AOG.0000228960.16678.bd.

16. Hedderson MM, Weiss NS, Sacks DA, Pettitt DJ, Selby JV, Quesenberry CP, et al. Pregnancy weight gain and risk of neonatal complications: macrosomia, hypoglycemia, and hyperbilirubinemia. Obstet Gynecol. 2006 108(5):1153-61. https://doi.org/10.1097/01.aog.0000242568.75785.68.

17. Ye M, Liu Y, Cao X, Yao F, Liu B, Li Y, et al. The utility of HbA1c for screening gestational diabetes mellitus and its relationship with adverse pregnancy outcomes. Diabetes Res Clin Pract. 2016;114:43-9. https://doi.org/10.1016/j. diabres.2016.02.007.

18. Lapolla A, Dalfra MG, Bonomo M, Castiglioni MT, Di Cianni G, Masin M, et al. Can plasma glucose and $\mathrm{HbA1c}$ predict fetal growth in mothers with different glucose tolerance levels? Diabetes Res Clin Pract. 2007;77(3):46570. https://doi.org/10.1016/j.diabres.2007.01.022.

19. Pietryga M, Brazert J, Wender-Ozegowska E, Dubiel M, Gudmundsson S. Placental Doppler velocimetry in gestational diabetes mellitus. J Perinat Med. 2006;34(2):108-10. https://doi.org/10.1515/jpm.2006.019.

20. Djelmis J, Blajic J, Bukovic D, Pfeifer D, Ivanisevic M, Kendic S, et al. Glycosylated hemoglobin and fetal growth in normal, gestational and insulin dependent diabetes mellitus pregnancies. Coll Antropol. 1997; 21(2):621-9.

21. Ott R, Stupin JH, Loui A, Eilers E, Melchior K, Rancourt RC, et al. Maternal overweight is not an independent risk factor for increased birth weight, leptin and insulin in newborns of gestational diabetic women: observations from the prospective 'EaCH' cohort study. BMC Pregnancy Childbirth. 2018; 18(1):250. https://doi.org/10.1186/s12884-018-1889-8.

22. Barquiel B, Herranz L, Hillman N, Burgos MA, Grande C, Tukia KM, et al. $\mathrm{HbA} 1 \mathrm{c}$ and gestational weight gain are factors that influence neonatal outcome in mothers with gestational diabetes. J Women's Health. 2002; 2016. https://doi.org/10.1089/jwh.2015.5432

23. Mikkelsen MR, Nielsen SB, Stage E, Mathiesen ER, Damm P. High maternal $\mathrm{HbA1c}$ is associated with overweight in neonates. Dan Med Bull. 2011;58(9):A4309.

24. Gandhi RA, Brown J, Simm A, Page RC, Idris I. HbA1c during pregnancy: its relationship to meal related glycaemia and neonatal birth weight in patients with diabetes. Eur J Obstet Gynecol Reprod Biol. 2008;138(1):45-8. https://doi.org/10.1016/j.ejogrb.2007.08.011.

25. Farrar D, Simmonds M, Bryant M, Sheldon TA, Tuffnell D, Golder S, et al. Hyperglycaemia and risk of adverse perinatal outcomes: systematic review and meta-analysis. BMJ (Clinical research ed). 2016;354:14694. https://doi.org/ 10.1136/bmj.i4694.

26. Hyperglycemia and Adverse Pregnancy Outcome (HAPO) Study: associations with neonatal anthropometrics. Diabetes. 2009:58(2):453-9. https://doi.org/10.2337/db08-1112.

27. Silva AL, Amaral AR, Oliveira DS, Martins L, Silva MR, Silva JC. Neonatal outcomes according to different therapies for gestational diabetes mellitus. J Pediatr. 2017:93(1):87-93. https://doi.org/10.1016/j.jped.2016.04.004

28. Bogdanet D, Egan A, Reddin C, Kirwan B, Carmody L, Dunne F. ATLANTIC DIP: despite insulin therapy in women with IADPSG diagnosed GDM, desired pregnancy outcomes are still not achieved. What are we missing? Diabetes Res Clin Pract. 2018;136:116-23. https://doi.org/10.1016/j.diabres. 2017.12003

29. International Association of Diabetes and Pregnancy Study Groups recommendations on the diagnosis and classification of hyperglycemia in pregnancy. Diabetes Care. 2010;33(3):676-82. https://doi.org/10.2337/ dc09-1848.

30. Management of diabetes in pregnancy: standards of medical care in diabetes_2018. Diabetes Care. 2018:41(Supplement 1):S137-S43. https:// doi.org/10.2337/dc18-S013.

31. Blumer I, Hadar E, Hadden DR, Jovanovič L, Mestman JH, Murad MH, et al. Diabetes and pregnancy: an endocrine society clinical practice guideline. J Clin Endocrinol Metab. 2013;98(11):4227-49. https://doi.org/ 10.1210/jc.2013-2465.

32. Diabète programme Cantonal $V$. Recommendations pour la pratique clinique. 2017. 
33. Arditi C, Burnand B, Puder J. Recommendations pour la pratique clinique 2017. http://recodiab.ch/RPC22_diabete_gestationnel_20171102.pdf. Accessed 19 Sept 2018.

34. Wood JR, Kaminski BM, Kollman C, Beck RW, Hall CA, Yun JP, et al. Accuracy and precision of the Axis-Shield Afinion hemoglobin A1C measurement device. J Diabetes Sci Technol. 2012;6(2):380-6. https://doi.org/10.1177/ 193229681200600224.

35. Villar J, Cheikh Ismail L, Victora CG, Ohuma EO, Bertino E, Altman DG, et al. International standards for newborn weight, length, and head circumference by gestational age and sex: the newborn cross-sectional study of the INTERGROWTH-21st project. Lancet (London, England). 2014; 384(9946):857-68. https://doi.org/10.1016/s0140-6736(14)60932-6.

36. Tolsa J-F, Truttmann A, Giannoni E, Muehlethaler V, Fischer C, Roth-Kleiner M. Vademecum de Neonatologie. 12 Decembre 2013 ed: CHUV Lausanne; 2013.

37. Peduzzi P, Concato J, Kemper E, Holford TR, Feinstein AR. A simulation study of the number of events per variable in logistic regression analysis. J Clin Epidemiol. 1996:49(12):1373-9.

38. Mosca A, Paleari R, Dalfra MG, Di Cianni G, Cuccuru I, Pellegrini G, et al. Reference intervals for hemoglobin A1c in pregnant women: data from an Italian multicenter study. Clin Chem. 2006;52(6):1138-43. https://doi.org/10. 1373/clinchem.2005.064899.

39. Haydar A, Vial Y, Baud D, Desseauve D. Evolution of cesarean section rates according to Robson classification in a swiss maternity hospital. Rev Med Suisse. 2017;13(580):1846-51.

40. Maier JT, Schalinski E, Gauger U, Hellmeyer L. Antenatal body mass index (BMI) and weight gain in pregnancy - its association with pregnancy and birthing complications. J Perinat Med. 2016;44(4):397-404. https://doi.org/10. 1515/jpm-2015-0172

41. Shen J, Zhang Z, Chen K, Lu M, Qian Q, Liu P, et al. Prepregnancy obesity status and risks on pregnancy outcomes in Shanghai: a prospective cohort study. Medicine. 2018;97(40):e12670. https://doi.org/10.1097/md. 0000000000012670.

42. Goto E. Dose-response association between maternal body mass index and small for gestational age: a meta-analysis. J Matern Fetal Neonatal Med. 2017;30(2):213-8. https://doi.org/10.3109/14767058.2016.1169519.

43. Li N, Liu E, Guo J, Pan L, Li B, Wang P, et al. Maternal prepregnancy body mass index and gestational weight gain on pregnancy outcomes. PLoS One. 2013;8(12):e82310. https://doi.org/10.1371/journal.pone.0082310.

44. Gante I, Amaral N, Dores J, Almeida MC. Impact of gestational weight gain on obstetric and neonatal outcomes in obese diabetic women. BMC Pregnancy Childbirth. 2015;15:249. https://doi.org/10.1186/s12884015-0692-z.

45. Bianchi C, de Gennaro G, Romano M, Aragona M, Battini L, Del Prato S, et al. Pre-pregnancy obesity, gestational diabetes or gestational weight gain: which is the strongest predictor of pregnancy outcomes? Diabetes Res Clin Pract. 2018;144:286-93. https://doi.org/10.1016/j.diabres.2018.08.019.

46. Cosson E, Cussac-Pillegand C, Benbara A, Pharisien I, Nguyen MT, Chiheb S, et al. Pregnancy adverse outcomes related to pregravid body mass index and gestational weight gain, according to the presence or not of gestational diabetes mellitus: a retrospective observational study. Diabetes Metab. 2016;42(1):38-46. https://doi.org/10.1016/j.diabet.2015.06.001.

47. Ludwig DS, Currie J. The association between pregnancy weight gain and birthweight: a within-family comparison. Lancet (London, England). 2010; 376(9745):984-90. https://doi.org/10.1016/s0140-6736(10)60751-9.

48. Simpson JW, Lawless RW, Mitchell AC. Responsibility of the obstetrician to the fetus. II. Influence of prepregnancy weight and pregnancy weight gain on birthweight. Obstet Gynecol. 1975;45(5):481-7.

49. Hung TH, Chen SF, Hsu JJ, Hsieh TT. Gestational weight gain and risks for adverse perinatal outcomes: a retrospective cohort study based on the 2009 Institute of Medicine guidelines. Taiwan J Obstet Gynecol. 2015;54(4):421-5. https://doi.org/10.1016/j.tjog.2015.06.010.

50. Johnson J, Clifton RG, Roberts JM, Myatt L, Hauth JC, Spong CY, et al. Pregnancy outcomes with weight gain above or below the 2009 Institute of Medicine guidelines. Obstet Gynecol. 2013;121(5):969-75. https://doi.org/ 10.1097/AOG.0b013e31828aea03.

51. Katon J, Williams MA, Reiber G, Miller E. Antepartum A1C, maternal diabetes outcomes, and selected offspring outcomes: an epidemiological review. Paediatr Perinat Epidemiol. 2011;25(3):265-76. https://doi.org/10.1111/j.13653016.2011.01195.x.

52. Barnes RA, Edghill N, Mackenzie J, Holters G, Ross GP, Jalaludin BB, et al. Predictors of large and small for gestational age birthweight in offspring of women with gestational diabetes mellitus. Diabet Med. 2013;30(9):1040-6. https://doi.org/10.1111/dme.12207.

53. Santé des nouveau-nés 2008. https://www.bfs.admin.ch/bfs/fr/home/ statistiques/catalogues-banques-donnees/communiques-presse. assetdetail.32981.html. Accessed 20 June 2019.

54. Martin JA, Hamilton BE, Sutton PD, Ventura SJ, Mathews TJ, Osterman MJ. Births: final data for 2008. Natl Vital Stat Rep. 2010;59(1):1, 3-71.

55. Bhutani VK, Stark AR, Lazzeroni LC, Poland R, Gourley GR, Kazmierczak S, et al. Predischarge screening for severe neonatal hyperbilirubinemia identifies infants who need phototherapy. J Pediatr. 2013;162(3):477-82.e1. https://doi.org/10.1016/j.jpeds.2012.08.022.

56. Schulman J, Braun D, Lee HC, Profit J, Duenas G, Bennett MV, et al. Association between neonatal intensive care unit admission rates and illness acuity. JAMA Pediatr. 2018;172(1):17-23. https://doi.org/10.1001/ jamapediatrics.2017.3913.

57. Harrison WN, Wasserman JR, Goodman DC. Regional variation in neonatal intensive care admissions and the relationship to bed supply. J Pediatr. 2018;192:73-9 e4. https://doi.org/10.1016/j.jpeds.2017.08.028.

58. Hughes RC, Rowan J, Florkowski CM. Is there a role for HbA1C in pregnancy? Curr Diab Rep. 2016;16(1):5. https://doi.org/10.1007/s11892-0150698-y.

59. Headen I, Cohen AK, Mujahid M, Abrams B. The accuracy of self-reported pregnancy-related weight: a systematic review. Obes Rev. 2017;18(3):350-69. https://doi.org/10.1111/obr.12486.

\section{Publisher's Note}

Springer Nature remains neutral with regard to jurisdictional claims in published maps and institutional affiliations.

Ready to submit your research? Choose BMC and benefit from:

- fast, convenient online submission

- thorough peer review by experienced researchers in your field

- rapid publication on acceptance

- support for research data, including large and complex data types

- gold Open Access which fosters wider collaboration and increased citations

- maximum visibility for your research: over $100 \mathrm{M}$ website views per year

At BMC, research is always in progress.

Learn more biomedcentral.com/submissions 